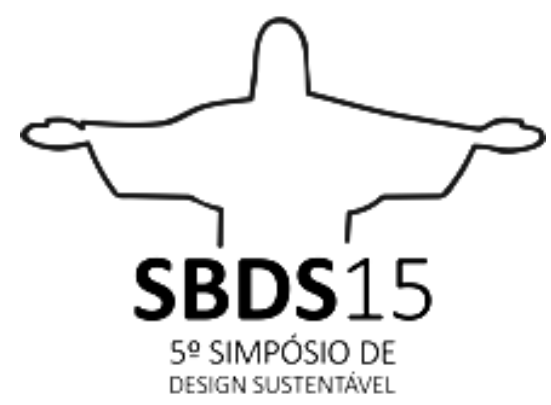

Rio de Janeiro, 11 de novembro a 13 de novembro de 2015

\title{
ESTRATÉGIAS DE APRENDIZAGEM NA DISCIPLINA DESIGN E SUSTENTABILIDADE
}

\author{
Ana Veronica Pazmino \\ UFSC \\ ana.veronica@ufsc.br
}

\begin{abstract}
Resumo: Este artigo apresenta a aplicação de estratégias de ensinagem com ênfase na aprendizagem significativa na disciplina de Design e Sustentabilidade no curso de graduação em design da UFSC. Trata-se de estratégias que visam tornar possível o ato cognitivo de aprender, para que os alunos possam compreender de forma significativa a multidisciplinaridade do campo do design, e para que o tema da sustentabilidade seja motivo de reflexão. $O$ artigo também trata as premissas teóricas de ensino e aprendizagem e da necessidade do professor colaborar com a aprendizagem dos alunos e melhorar a qualidade do ensino por meio de estratégias e atividades que ajudem na obtenção de uma aprendizagem significativa, tornando-o um facilitador na produção do conhecimento.
\end{abstract}

Palavras-chave: Pedagogia do Design, Estratégias de Ensinagem, Design e Sustentabilidade.

Abstract:This paper presents the application of teaching strategies with emphasis on meaningful learning in the discipline of Design and Sustainability in undergraduate degree in design at UFSC. These are strategies that aim to make possible the cognitive act of learning, so that students can understand significantly multidisciplinary design field, and that the issue of sustainability is cause for reflection. The article also deals with the theoretical assumptions of teaching and learning and the need for teachers to collaborate with student learning and improve the quality of education through strategies and activities that help in achieving a meaningful learning, making it a facilitator in production knowledge.

Keywords: Pedagogy of Design, Teaching Strategies, Design and Sustainability.

\section{ENSINO E APRENDIZAGEM}

O professor tem um papel fundamental na qualidade do ensino, a ação docente deve ser significativa, relevante e competente. 
Para Masetto (2001, p.84) a qualidade da formação do profissional exige muito mais dos alunos que apenas uma reprodução das informações que eles receberam em sala da aula. Para elevar a qualidade do ensino de graduação é preciso buscar atividades pedagógicas que sejam mais eficientes e mais eficazes para colaborar com a aprendizagem dos alunos e melhorar a qualidade dos cursos.

Pimenta e Anastasiou (2008) mencionam que há certo consenso de que docência no ensino superior não requer formação no campo de ensinar. Para as autoras nesse conceito, o professor é aquele que ensina, ou seja, dispõe os conhecimentos aos alunos. Elas ainda comentam que na maioria das instituições de ensino superior, incluindo as universidades, embora os professores possuam experiências significativas e mesmo anos de estudos em suas áreas específicas, predomina o despreparo e até um desconhecimento científico do que seja o processo de ensino e de aprendizagem pelo qual são responsáveis ao assumirem a docência.

O que caracteriza o exercício da docência universitária pode ser mostrado nas palavras de BENEDITO (1995, p. 120).

[...] o professor universitário aprende a sê-lo mediante um processo de socialização em parte intuitiva, autodidata ou, o que é pior, seguindo a rotina dos "outros". Isto deve-se, sem dúvida à inexistência de uma formação específica como professor universitário.

Para Gil (2008) o desempenho dos docentes é questionado atualmente devido ao surgimento de uma visão mais crítica do ensino, na medida em que maior número de pessoas chega à universidade, que os cursos se tornam mais específicos e que o controle sobre a qualidade do ensino e a capacitação docente decai. O que conduz a necessidade do professor universitário adquirir conhecimentos e habilidades de natureza pedagógica.

Freire (1996) sustentava desafiar o educando de forma a produzir a profundidade na compreensão e na interpretação dos fatos, possibilitando que o pensar certo supere o pensar ingênuo. Para que isto aconteça Freire propõe por em prática de forma metódica a capacidade de indagar, comparar, duvidar e aferir, já que tanto mais curioso o sujeito mais crítico pode fazer o bom senso.

As ideias mencionadas por Freire têm convergência com Masetto $(2001$, p.86) que apresenta algumas características básicas da aprendizagem no ensino universitário. Inicialmente, ele considera que a aprendizagem pressupõe, por parte do aluno, aquisição e domínio de um conjunto de conhecimentos, métodos e técnicas científicas de forma crítica. Em seguida, ele considera integrar o processo ensinoaprendizagem com a atividade de pesquisa tanto do aluno como do professor.

$\mathrm{O}$ autor também menciona que dificilmente o aluno incluirá a investigação em seu processo de aprendizagem se o professor também não o fizer em sua atividade docente, ou seja, se o professor não aprender a atualizar seus conhecimentos por meio de pesquisas, de leituras, de participação em projetos de pesquisa, de reflexões pessoais, e de participação em congressos.

Masetto $(2001$, p. 86) destaca que toda aprendizagem, para que realmente aconteça, precisa ser significativa, ou seja, precisa envolver o aluno como indivíduo como um todo: ideias, repertório, inteligência, sentimentos, cultura, sociedade. Isto conduz a percepção da necessidade do professor universitário adquirir conhecimentos e habilidades pedagógicas.

A teoria da aprendizagem significativa mostra-se adequada para o ensino de design. Pois, ela visa a aquisição de novos significados, considerando que o processo de aquisição de informações por parte do aluno resulta numa alteração, quer das ideias recentemente adquiridas, quer do aspecto especificamente relevante da estrutura cognitiva, à qual estão ligadas as novas informações, considerando que a significação é uma questão individual. A seguir é apresentado um resumo da teoria significativa para maior entendimento.

\subsection{Aprendizagem significativa}

Para Ausubel (2003) defensor desta teoria de aprendizagem cognitiva, o fator isolado que mais influencia na aprendizagem é aquilo que o aluno já sabe, cabendo ao professor identificar para ensinar de acordo. Nesse aspecto, novas ideias ou informações podem ser aprendidas e retidas, na medida em que conceitos relevantes estejam adequadamente claros e disponíveis na estrutura cognitiva do aluno, e funcionem como ponto de ancoragem às novas ideias e conceitos. 
Para Moreira (1999), o conceito central da teoria de Ausubel é que a aprendizagem significativa é um processo por meio do qual uma nova informação relaciona-se com um aspecto especificamente relevante da estrutura de conhecimento do aluno. Ou seja, este processo envolve a interação da nova informação com uma estrutura de conhecimento específica existente na estrutura cognitiva do indivíduo.

Ausubel (2003) recomenda o uso de organizadores prévios que sirvam de âncora para a nova aprendizagem e levem ao desenvolvimento de conceitos que facilitem a aprendizagem subsequente. $O$ uso de organizadores seria uma estratégia para deliberadamente manipular a estrutura cognitiva, a fim de facilitar a aprendizagem significativa. Organizadores prévios podem ser materiais introdutórios em nível alto de abstração e generalidade apresentado antes do material a ser aprendido em si. A função do organizador prévio é a de ser uma ponte cognitiva entre o que o aprendiz já sabe e o que ele deve saber.

Há necessidade da preparação do docente em conhecer estratégias de aprendizagem de forma que o processo de ensino-aprendizagem dos conceitos, ideias ou informações do campo do design sejam significativos, e que o aluno apreenda informações adequadas que o auxiliem na tomada de decisões relacionadas à sustentabilidade.

\section{ESTRATÉGIAS DE APRENDIZAGEM OU ENSINAGEM}

As estratégias de aprendizagem ou de ensinagem visam à consecução dos objetivos do planejamento de ensino. Assim, as estratégias são os procedimentos a serem utilizados para facilitar o processo de aprendizagem e buscam alcançar uma aprendizagem significativa por parte dos alunos.

Buscando uma maior motivação dos alunos, torna-se necessário conhecer o feedback dos mesmos; identificar o nível de conhecimentos e expectativas deles. Assim, uma das estratégias que será apresentada no artigo o Estudo de Texto que permite a construção de conceitos feitos coletivamente. É uma forma de obter um retorno dos alunos, bem como dos mesmos desenvolverem o respeito pela opinião do grupo e fomentar o hábito da leitura e interpretação de textos.

É habitual perceber na universidade que os alunos chegam avesso a leitura e interpretação de textos, por isto recomenda-se que o texto a ser trabalhado seja escolhido depois de conhecer a turma, pois assim, se o hábito de leitura não estiver interiorizado pode-se escolher um texto simples e dinâmico. Por outro lado, se a turma mostra um hábito de leitura e facilidade na interpretação pode ser passado um texto mais complexo. A estratégia de Estudo de Texto é mostrada no Quadro 1.

\begin{tabular}{|c|c|}
\hline DESCRIÇÃO & $\begin{array}{l}\text { É a exploração de idéias de um autor a partir do estudo critico de um texto } \\
\text { e/ou a busca de informaçōes e a exploração de idéias de autores } \\
\text { estudados. }\end{array}$ \\
\hline $\begin{array}{l}\text { OPERAÇÕES DE } \\
\text { PENSAMENTO } \\
\text { (Predominantes) }\end{array}$ & $\begin{array}{l}\text { Identificaçāo/Obtenção e organizaçāo dos dados/Interpretação/ } \\
\text { Critica/Análise/Reelaboraçāo/Resumo. }\end{array}$ \\
\hline $\begin{array}{l}\text { DINÂMICA DA } \\
\text { ATIVIDADE }\end{array}$ & 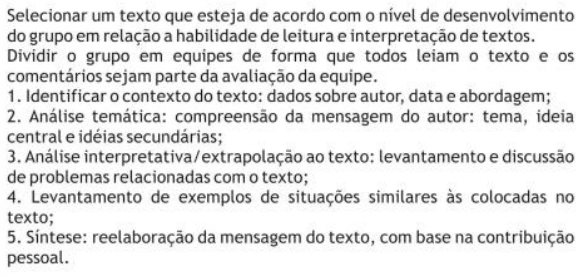 \\
\hline AVALIAÇÃO & $\begin{array}{l}\text { Participação oral, com comentário do aluno, tendo em vista a vontade de } \\
\text { particicipaçāo, habilidades de compreensăo, análise, sintese, julgamento, } \\
\text { interferencias, troca de informaçōes com os outros participantes. } \\
\text { Produçấo escrita de respostas a perguntas sobre o texto. }\end{array}$ \\
\hline
\end{tabular}

Quadro 1 Estratégia da aprendizagem: Estudo de Texto

Fonte: Adaptado de Anastasiou (2006, p.80).

A estratégia cine educação busca utilizar filmes como meio de reflexão, comparação, e aproximação de realidades e contextos que permitam aprofundar os conceitos da disciplina. Não pode ser visto como um meio de ocupar uma aula e preencher um espaço no plano de ensino. Os títulos dos filmes devem ser previamente selecionados e assistidos pelo professor. A estratégia de cine educação é mostrada no Quadro 2. 


\section{Quadro 2 Estratégia da aprendizagem: Cine educação}

\begin{tabular}{|c|c|}
\hline DESCRIÇÃO & $\begin{array}{l}\text { É a análise de um tema ou problema por meio do uso de um filme ou vídeo servindo para } \\
\text { introduzir, explicitar, repensar, enxergar ou complementar algum assunto a ser trabalhado } \\
\text { com os alunos. }\end{array}$ \\
\hline $\begin{array}{l}\text { OPERAÇ̃̃ES DE } \\
\text { PENSAMENTO } \\
\text { (Predominantes) }\end{array}$ & Análise/Interpretação/Crítica/Levantamento de hipóteses/ Comparação/Resumo \\
\hline $\begin{array}{l}\text { DINÂMICA DA } \\
\text { ATIVIDADE }\end{array}$ & $\begin{array}{l}\text { 1. Contextualizar o tema a ser tratado e a visão do filme ou documentário; } \\
\text { 2. Esclarecer os objetivos a serem alcançados com o filme } \\
\text { 3. O filme deve estar de acordo com o tema a ser tratado ea maturidade dos alunos; } \\
\text { 4. Estabelecer a discussão ou entrega de uma resenha critica para complementar o assunto } \\
\text { da disciplina. (em caso de resenha passar com antecedência os elementos da mesma) } \\
\text { 5. Permitir a interdisciplinaridade com a contribuição de pontos de vista de outras } \\
\text { disciplinas. }\end{array}$ \\
\hline AVALIAÇÃO & $\begin{array}{l}\text { O grupo será avaliado pelo professor por meio de critérios em relação aos comentários orais } \\
\text { (argumentação sólida) ou escritos (resenha): } \\
\text { - clareza e coerência na exposição oral ou escrita; } \\
\text { - domino da problemática tratada; } \\
\text { - a complementaçấo com o tema da aula; } \\
\text { - argumento para justificar a critica ado assunto } \\
\text { - atendimento aos elementos de uma resenha. }\end{array}$ \\
\hline
\end{tabular}

Fonte: Elaborado pela autora, com base na pesquisa realizada.

Para esta estratégia se recomenda um comentário escrito por meio de uma resenha crítica que permite além de apresentar informações selecionadas e resumidas sobre o conteúdo do filme, também apresenta comentários, avaliações e expressa a opinião do aluno. Os elementos da resenha devem ser passados e explicados com antecedência.

Alguns elementos para uma resenha são:

(Autor da resenha/ aluno)

Data da resenha

Titulo do filme ou vídeo:

Gênero:

Disciplinas Relacionadas:

Contextualização do filme:

Tema do filme em relação aos assuntos da disciplina:

Estrutura do filme descrição do início meio e fim dos aspectos mais importantes;

Crítica do filme, a impressão e opinião do autor da resenha.

A seguir são relatadas as aplicações e avaliações das estratégias aplicadas com uma turma na disciplina de design e sustentabilidade no curso de design da UFSC.

\section{RELATO DA APLICAÇÃO DAS ESTRATÉGIAS NA DISCIPLINA DE DESIGN E SUSTENTABILIDADE}

A experiência da aplicação ocorreu na disciplina de design e sustentabilidade no curso de design da UFSC para uma turma composta por 24 alunos durante 18 encontros entre os dias 04/09/14 e 11/12/14. A disciplina Design e Sustentabilidade é obrigatória e teórica, tem uma carga horária total de $54 \mathrm{~h}$ (3h/aula). Dentro da grade do curso a disciplina pode ser cursada em qualquer fase, por este motivo as turmas são variadas, com alunos do 1음 ao 4 으o

No plano de ensino o objetivo geral da disciplina é compreender a complexidade da sustentabilidade e sua relação com a responsabilidade social e ética do designer. Os objetivos específicos da disciplina são:

1. Compreender a problemática ambiental;

2. Conhecer o percurso cronológico do novo paradigma ambiental;

3. Conhecer as propostas de novos cenários sustentáveis;

4. Conhecer os princípios do eco-design e da sustentabilidade;

5. Conhecer estratégias de desenvolvimento de serviços sustentáveis;

6. Compreender a complexidade ambiental e a importância da interdisciplinaridade.

Para que os alunos alcancem os objetivos e para incentivar a participação continua, o planejamento de ensino inclui estratégias de aprendizagem tais como: Estudo de Texto; Estudo de caso, Aula expositiva 
dialogada e cine educação. Neste artigo será relatada a aplicação das estratégias de estudo de texto e cine educação descritas no item 2 que servem para que os alunos alcancem os objetivos 1, 3 e 6 .

No primeiro dia de aula na apresentação do plano de ensino foi explicada a estratégia de estudo de texto que corresponde a $30 \%$ da nota bimestral, na qual os alunos devem escolher um título dos livros, ler os capítulos todas as semanas e comentar na aula seguinte. E da estratégia cine educação onde os alunos deviam assistir a 5 filmes ao longo do semestre em datas específicas e fazer uma resenha crítica postada no moodle (ambiente virtual) atendendo os elementos da resenha mencionados no item 2 deste artigo.

\subsection{Avaliação da professora}

A avaliação da estratégia do estudo de texto está relacionada a dois critérios: argumentação em relação ao comentário e a clareza e coerência da exposição. Para facilitar a avaliação em uma turma é utilizada uma tabela como mostrado no Quadro 3 onde consta o nome do aluno e círculos que quando atendem aos dois critérios é preenchido em azul. São 8 círculos para o primeiro bimestre e 7 para o segundo bimestre, quem tiver marcações em todos os círculos obtém 3 pontos em cada bimestre. Para marcações inferiores é feita uma relação proporcional.

Os comentários voluntários dos alunos levam em torno de 30 a $40 \mathrm{~min}$ (1h aula). A estratégia é realizada no início da aula. Porém, se é uma turma com muitos alunos os comentários podem ser postados no ambiente moodle em formato de blog como mostra a Figura 1.

Quadro 3 Marcação do estudo de texto por aluno

\begin{tabular}{|l|l|l|l|}
\hline Design e Sust. & Nota 1 & Nota 2 \\
\hline Aluno & 000000000000 & 3 & 3 \\
\hline Aluno & 000000000000 & 1,5 & 1,3 \\
\hline
\end{tabular}

Fonte: Elaborado pela autora, com base na pesquisa realizada.

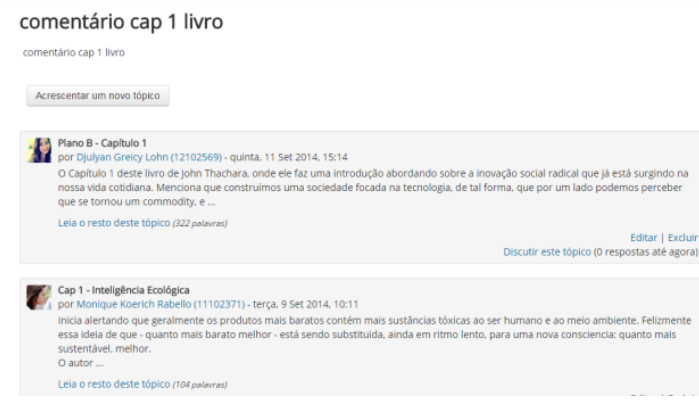

Figura 1 ambiente moodle blog estudo de texto

Fonte: Elaborado pela autora, com base na pesquisa realizada.

Foram lidos 3 livros, e quando um terminou podia ser substituído por outro. O Quadro 4 mostra os títulos dos livros, principais características, número de capítulos e número de alunos que o escolheram.

Quadro 4 Livros lidos no estudo de texto

\begin{tabular}{|c|c|c|c|}
\hline Título do livro & Principais características & № de cap. & № de alunos \\
\hline $\begin{array}{l}\text { LEONARD, Annie. A história das coisas: da } \\
\text { natureza ao lixo, o que acontece com tudo } \\
\text { que consumimos. Rio de Janeiro: Zahar, } 2011 . \\
255 \text { p. }\end{array}$ & $\begin{array}{l}\text { É um livro que descreve os impactos ambientais ao } \\
\text { longo do ciclo de vida por meio de exemplos e } \\
\text { dados de outras disciplinas como ecologia, química } \\
\text { etc. A linguagem é simples, porém os capítulos são } \\
\text { extensos de umas 50p. Esse é um problema para } \\
\text { alunos que não tem o hábito da leitura. }\end{array}$ & 5 & \multirow[t]{2}{*}{6} \\
\hline $\begin{array}{l}\text { MANZINI, Ezio. Design para inovação social e } \\
\text { sustentabilidade. Rio de Janeiro. e-papers, } \\
\text { 2008. 100.p. }\end{array}$ & $\begin{array}{l}\text { Livro de poucas páginas, com uma nova } \\
\text { abordagem que chama a atenção dos alunos em } \\
\text { relação a proposta de novos cenários mostrando } \\
\text { uma visão mais inovadora da sociedade. }\end{array}$ & 4 & \\
\hline $\begin{array}{l}\text { THACKARA, J. Plano B: o design e as } \\
\text { alternativas viáveis em um mundo complexo. } \\
\text { São Paulo: Saraiva: Versar, } 2008 .\end{array}$ & $\begin{array}{l}\text { Livro que trata de várias problemáticas ambientais, } \\
\text { a leitura é mais densa, e precisa de reflexão. }\end{array}$ & 14 & 18 \\
\hline
\end{tabular}

Fonte: Elaborado pela autora, com base na pesquisa realizada. 
A forma de avaliação é igual ao Quadro 3. O número de alunos e a leitura dos livros são mostrados a seguir no Quadro 5 e no Gráfico 1.

Quadro 5 relação de número de alunos e número de leituras

\begin{tabular}{|c|c|c|}
\hline Número de alunos & Leitura semestre & Porcentagem \\
\hline 8 & 7 & $33 \%$ \\
\hline 5 & 0 & $21 \%$ \\
\hline 3 & 10 & $12 \%$ \\
\hline 3 & 4 & $12 \%$ \\
\hline 3 & 2 & $12 \%$ \\
\hline 2 & 8 & $8 \%$ \\
\hline 24 & & \\
\hline
\end{tabular}

Fonte: Elaborado pela autora, com base na pesquisa realizada.

Gráfico 1 Porcentagem dos alunos na estratégia de estudo de texto

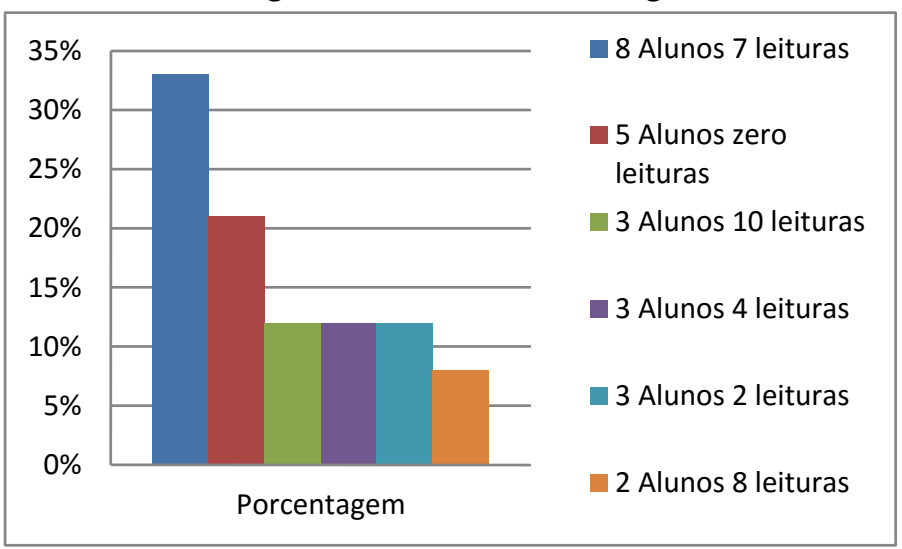

Fonte: Elaborado pela autora, com base na pesquisa realizada.

$53 \%$ dos alunos fizeram o estudo de texto entre 7 e 10 vezes o que mostra que metade da turma respondeu positivamente a estratégia. Já $47 \%$ contribuíram pouco com a estratégia sendo que não leram e comentaram ou fizeram apenas 4 participações. Mesmo que o peso da atividade foi de $30 \%$ da nota bimestral isso não incentivou os alunos.

$12 \%$ Dos alunos realizaram de forma adequada a estratégia, lendo e comentando em todos os encontros. Já o número de alunos sem participações nesta disciplina foi de $21 \%$, cabe salientar, que os alunos que não comentaram, nunca tiveram aulas com a professora, sendo que os outros alunos no semestre passado já conheciam a estratégia e estavam estimulados a participar.

Para a estratégia de cine educação foi colocado no plano de ensino 5 filmes e ou vídeo que deviam ser assistidos em casa, o link foi disponibilizado pelo moodle. Os alunos deviam fazer resenhas e postar no ambiente virtual.

O quadro 6 mostra o título do filme, principais características, número de alunos que postaram a resenha e porcentagem de alunos em relação ao filme.

Quadro 6 relação de número de alunos resenhas postadas dos filmes

\begin{tabular}{|c|c|c|c|}
\hline Título filme/ ou vídeo - tempo & Principais características & № de alunos & $\%$ dos alunos \\
\hline $\begin{array}{l}\text { A história das coisas } 20^{\prime} \\
\text { ou } \\
\text { Um oceano de plástico - A sujeira se } \\
\text { acumula no Lixão do Pacífico 7' }\end{array}$ & $\begin{array}{l}\text { Vídeos de pouca duração mostrando o } 10 \text { apresenta a } \\
\text { problemática ambiental e conceitos de obsolescência, } \\
\text { consumo e descarte. O } 20 \text { o mostra o impacto dos } \\
\text { plásticos no meio ambiente. }\end{array}$ & 14 & $58 \%$ \\
\hline Obsolescência programada & $\begin{array}{l}\text { Filme que mostra como a indústria se compromete na } \\
\text { década de } 50 \text { a produzir produtos com reduzido tempo } \\
\text { de vida para que incentivar consumo. Um exemplo é } \\
\text { da lâmpada que foi produzida para durar } 100 \text { anos e } \\
\text { atualmente tem uma duração de meses. O efeito do } \\
\text { filme traz muita reflexão para a ação do designer. }\end{array}$ & 20 & $83 \%$ \\
\hline A farsa do aquecimento global & $\begin{array}{l}\text { Trata de um assunto polemica que esta dividindo a } \\
\text { classe científica, por um lado os defensores do } \\
\text { aquecimento global e os que no filme mostram que } \\
\text { não existe o aquecimento e que isso foi criado pela }\end{array}$ & 15 & $62 \%$ \\
\hline
\end{tabular}




\begin{tabular}{|l|l|c|c|}
\hline & $\begin{array}{l}\text { indústria e governos para incentivar o consumo de } \\
\text { novos produtos e tecnologias. }\end{array}$ & 15 & \\
\hline Addicted to plastics & $\begin{array}{l}\text { Mostra como o plástico tem sido visto como material } \\
\text { que oferecia liberdade pelo conceito de descartável, } \\
\text { mas que em contra partida trouxe um excesso de lixo } \\
\text { com graves consequências. }\end{array}$ & $\begin{array}{l}\text { Documentário em que vários formadores de opinião } \\
\text { desde cientistas a místicos mostram que a terra tem } \\
\text { todo o tempo do mundo, mas que o ser humano está } \\
\text { de passagem e que com suas ações compromete a vida } \\
\text { humana das próximas gerações. }\end{array}$ & $79 \%$ \\
\hline
\end{tabular}

Fonte: Elaborado pela autora, com base na pesquisa realizada.

A estratégia da resenha tinha um peso de $20 \%$, em média temos que $70 \%$ dos alunos fizeram e postaram a resenha. A avaliação em relação à qualidade da resenha foi realizada a partir de dois critérios: redação crítica e atendimento aos elementos da resenha. 0 quadro 7 mostra a relação de qualidade das resenhas e número de alunos.

Quadro 7 relação de número de alunos x qualidade das resenhas postadas

\begin{tabular}{|c|c|c|c|}
\hline Excelente & Bom & Regular & Não fez \\
\hline 8 Alunos & 8 Alunos & 2 Alunos & 6 Alunos \\
\hline $33 \%$ & $33 \%$ & $8 \%$ & $25 \%$ \\
\hline
\end{tabular}

Fonte: Elaborado pela autora, com base na pesquisa realizada.

Pode-se perceber um número próximo entre as duas estratégias para os alunos que não realizaram as atividades $21 \%$ para estudo de texto e $25 \%$ para cine educação. E o número de alunos que fizeram excelentes e boas resenhas $66 \%$ ultrapassa o número de alunos que leu e comentou os textos $56 \%$. Pode-se afirmar que o comprometimento dos alunos independe das estratégias, estaria mais relacionado com a responsabilidade e comprometimento com o aprendizado. Os alunos que fazem parte dos $33 \%$ tem uma postura amadurecida, são críticos e contribuem socializando com a professora outros filmes e livros sobre o assunto da disciplina, mostrando um "espiral do conhecimento" 1 .

A seguir dois trechos da resenha mostrando a posição crítica de dois alunos que tiveram excelente qualidade.

A reportagem é bastante interessante pois mostra dados alarmantes do problema causado pela eliminação do lixo, principalmente o plástico e como exatamente muitos animais são afetados. As imagens e a revelação da degradação da vida marinha cumprem seu papel de surpreender e chocar o espectador e faze-lo indagar o consumo despreocupado de produtos descartáveis e a consequente eliminação do lixo do modo como ocorre atualmente. Ao mesmo tempo em que as imagens são tristes, a reportagem sem dúvida acaba sendo uma ótima proposta de sensibilização.

(“Um oceano de plástico - A sujeira se acumula no Lixão do Pacífico")

Ainda que o documentário aborde poucos exemplos ele mostra com bastante clareza como o sistema da obsolescência programada já implícito na produção acontece. O sistema econômico capitalista não se sustentaria sem a obsolescência dos produtos causando enorme impacto global se este fosse radicalmente mudado, então a ideia de uma mudança cultural, a disseminação da informação e a busca constante por um ciclo de produção, consumo e descarte mais próximo ao ciclo natural, orgânico de reaproveitamento seria a saída para este problema. Porém esta mudança não será proveniente do setor produtivo, ela tem que partir do próprio consumidor, daí a importância da conscientização e da disseminação da informação.

(The Light Bulb Conspiracy - A conspiração da lâmpada)

A estratégia de cine educação foi bem acolhida pelos alunos, a maioria $71 \%$ postou as resenhas. Como os filmes podiam ser assistidos em casa os alunos comentaram que isso facilitava a atividade, já que podiam assistir na hora que queriam e podiam dar pausa para escrever algum detalhe, além de poder levantar e comer enquanto assistiam ao filme. $O$ curso de design não contempla no seu Projeto Pedagógico que $20 \%$ das horas sejam a distância, esta atividade de cine educação poderia ser aplicada nessa modalidade.

\footnotetext{
${ }^{1}$ Segundo Navega (2005) a espiral do conhecimento acontece quando temos a oportunidade de repensar as ideias e noções que havíamos assumido como verdadeiras quando iniciamos nossa jornada.
} 


\subsection{Avaliação dos alunos}

Para ter um melhor retorno da aplicação da estratégia, foi feita uma avaliação por parte de 15 alunos no dia 18/12 por meio de questionário. Sondar os interesses e experiências dos alunos serve para que as estratégias sejam aprimoradas ou substituídas para que os conteúdos sejam psicologicamente significativos. O aluno não precisava se identificar visando que seja sincero e sem pressão de ser identificado pelo seu comentário. O resultado está mostrado nos Quadros 8 a 16.

\section{Quadro 8 opinião dos alunos em relação à atividade}

\begin{tabular}{|l|r|r|}
\hline Qual a sua opinião de ler livro e debater em toda aula \\
\hline Muito bom, ajuda na reflexão e no aumento de conhecimento & $\mathbf{7}$ & $\mathbf{4 3 , 8 \%}$ \\
\hline Bom, os textos ajudam a entender a complexidade da sustentabilidade. & 4 & $25 \%$ \\
\hline Ruim, os textos não foram do meu interesse & 3 & 18,8 \\
\hline Não gostei da atividade & 2 & $12,5 \%$ \\
\hline
\end{tabular}

Fonte: Elaborado pela autora, com base na pesquisa realizada.

$68,8 \%$ dos alunos consideram ler e comentar bom e muito bom; $18,8 \%$ alegam que os textos não foram interessantes e 12,5\% não gostaram da atividade. O Quadro 9 mostra a motivação da leitura ou a falta dela para não leitura.

Quadro 9 opinião em relação à motivação da leitura e não leitura

\begin{tabular}{|l|r|r|}
\hline Marque a opção que combina com você? & $\mathbf{5}$ & $\mathbf{3 3 , 3} \%$ \\
\hline Li os textos por obrigação (nota) & 2 & $13,3 \%$ \\
\hline Li mas não comentei porque sou tímido/a & 4 & $26,6 \%$ \\
\hline Li por nota, mas gostei. & 2 & $13,3 \%$ \\
\hline Li e gostei, comentei porque achei interessante &
\end{tabular}

Fonte: Elaborado pela autora, com base na pesquisa realizada.

A avaliação mostra que $33,3 \%$ dos alunos que participaram da atividade pela nota, $26,6 \%$ afirmam ter lido por nota, mas de que gostaram. E 13,3\% são tímidos e outros leram e comentaram por gostarem. 0 Quadro 10 a seguir tenta verificar por parte dos alunos as vezes que participaram da atividade.

\section{Quadro 10 participação na atividade}

\begin{tabular}{|l|r|r|}
\hline Ao longo do semestre você participou comentando o texto \\
\hline Sempre & 2 & $14,2 \%$ \\
\hline Quase sempre & 7 & $\mathbf{5 0 \%}$ \\
\hline Pouquíssimas vezes & 4 & $28,5 \%$ \\
\hline Nunca & 1 & \\
\hline
\end{tabular}

Fonte: Elaborado pela autora, com base na pesquisa realizada.

O Quadro 10 mostra que 64\% sempre e quase sempre fizeram as leituras e comentaram, e que $28,5 \%$ leram pouquíssimas vezes. O livro mais interessante foi: Plano B: o design e as alternativas viáveis em um mundo complexo, o motivo principal os assuntos diferentes, e o livro menos interessante $A$ história das coisas por ser cansativo e repetitivo. O Quadro 11 mostra a opinião em relação à nota da estratégia.

\section{Quadro 11 Opinião sobre a nota da estratégia}

\begin{tabular}{|l|r|r|}
\hline 3 pontos da nota bimestral correspondiam pela estratégia, você considera \\
\hline Adequado & 7 & $46,6 \%$ \\
\hline Inadequado por não gostar de ler e comentar & 2 & \\
\hline Inadequado por ser uma nota elevada & 6 & $40 \%$ \\
\hline
\end{tabular}

Fonte: Elaborado pela autora, com base na pesquisa realizada. 
$53,3 \%$ Do grupo avaliado considera inadequada a nota, sendo que $40 \%$ acham a nota elevada (3 pontos). 0 restante considera adequado mesmo sendo uma nota elevada. O Quadro 12 mostra a opinião sobre as participações dos colegas.

\section{Quadro 12 Opinião sobre comentário dos colegas}

\begin{tabular}{|l|r|r|}
\hline Os comentários dos colegas & 14 & $\mathbf{9 3 , 3 \%}$ \\
\hline Considera interessante & 1 & \\
\hline Da vontade de ler o livro pelos comentários & & \\
\hline Não presta atenção aos comentários & \\
\hline
\end{tabular}

Fonte: Elaborado pela autora, com base na pesquisa realizada.

A maioria dos alunos considera interessante o comentário dos colegas, nesta turma diferentemente da outra turma avaliada, ninguém declara não prestar atenção aos colegas. Os alunos estão na quarta fase do curso e, portanto demonstram respeito pelos colegas, pode ser por terem criado maiores vínculos de amizade. O Quadro 13 mostra a avaliação da estratégia cine educação e o Quadro 14 avaliação da resenha que faz parte desta estratégia.

\section{Quadro 13 Opinião sobre a estratégia cine educação}

\begin{tabular}{|l|r|r|}
\hline \multicolumn{2}{|l|}{ Qual a sua opinião da estratégia cine educação } \\
\hline Muito boa ajuda na reflexão e no aumento de conhecimento & 4 & $25 \%$ \\
\hline Boa, ajuda a entender a complexidade da sustentabilidade. & 10 & $\mathbf{6 2 , 5 \%}$ \\
\hline Ruim, os filmes ou vídeos não foram do meu interesse & 2 & $12,5 \%$ \\
\hline Ruim, os filmes ou vídeos já tinha assistido & & \\
\hline Não gostei & & \\
\hline
\end{tabular}

Fonte: Elaborado pela autora, com base na pesquisa realizada.

Os dados mostram que a maioria dos alunos aprova a estratégia, com uma pequena porcentagem a mais do que a estratégia de texto. A pequena diferença também se apresenta entre os $12,5 \%$ que acham ruim enquanto $18,8 \%$ achavam isso da estratégia de texto.

Quadro 14 Opinião sobre a resenha da estratégia cine educação

\begin{tabular}{|l|l|r|}
\hline Qual a sua opinião da resenha cine educação & $\mathbf{7}$ & $\mathbf{4 6 , 6 \%}$ \\
\hline Muito boa ajuda na reflexão e escrita & 5 & $\mathbf{2 9 , 4 \%}$ \\
\hline Boa, ajudou a expor a opinião & 1 & \\
\hline Ruim não gosto de escrever & 2 & \\
\hline Não gostei & \\
\hline
\end{tabular}

Fonte: Elaborado pela autora, com base na pesquisa realizada.

Os dados têm relação com a avaliação da professora em que $70 \%$ fizeram as resenhas com boa qualidade. O Quadro 15 mostra o comportamento do aluno.

\section{Quadro 15 Opinião sobre o comportamento com a estratégia cine educação}

\begin{tabular}{|l|r|r|}
\hline Marque a opção que combina com você? & $\mathbf{7}$ & $\mathbf{4 6 , 6 \%}$ \\
\hline Assisti aos filmes e fiz a resenha por obrigação (nota) & & \\
\hline Assisti aos filmes e não fiz a resenha & 8 & $\mathbf{5 3 , 3 \%}$ \\
\hline Assisti alguns filmes e fiz a resenha & & \\
\hline Não assisti nem fiz a resenha por falta de tempo & & \\
\hline Não assisti nem fiz a resenha & \\
\hline
\end{tabular}

Fonte: Elaborado pela autora, com base na pesquisa realizada.

Apresentam responsabilidade em realizar a atividade por nota, alguns assumem ter participado parcialmente. Já o filme que mais gostaram foi "Obsolescência programada" por se tratar de um assunto 
novo e o menos interessante "A historia das coisas" por ser conhecido e não oferecer nada novo. O Quadro 16 apresenta a opinião em relação à nota da atividade cine educação.

Quadro 16 Opinião sobre a nota da estratégia cine educação

2 pontos da nota bimestral correspondiam pela estratégia, você considera

\begin{tabular}{|l|r|r|}
\hline Adequado & $\mathbf{1 3}$ & $\mathbf{8 6 , 6 \%}$ \\
\hline Inadequado & 2 & $13,3 \%$ \\
\hline
\end{tabular}

Fonte: Elaborado pela autora, com base na pesquisa realizada.

A maioria dos alunos considera adequada a nota existindo uma grande diferença em relação aos $40 \%$ de insatisfação da nota de três pontos da estratégia de estudo de texto. Na turma seguinte algumas mudanças foram realizadas para manter a turma mais satisfeita, a nota da estratégia de texto foi reduzida para dois pontos. São oferecidos mais títulos e o aluno pode sugerir um titulo relacionado. Nos filmes procurar oferecer vários títulos para que os alunos escolham e manter a resenha que oferece um material rico em premissas e argumentos.

\section{CONCLUSÃO}

Teixeira (2006) menciona que o único teste da qualidade de uma experiência de aprendizagem está no fato, dela ser bem ou mal sucedida em provocar uma mudança no comportamento do aluno. Essa mudança pode ocorrer em ações, pensamentos sentimentos e atitudes como resultado de uma "experiência de aprendizagem", isto é, por um método de ensino adequado. O artigo mostrou que as estratégias adotadas para a disciplina provocaram atitudes comportamentais em alguns alunos tais como: ler por ser interessante, prestar atenção aos colegas, adquirir novas ideias, escrever resenhas com argumentos, melhorando sua condição perceptual além de expor suas ideias.

As estratégias atendem os objetivos específicos da disciplina de design e sustentabilidade: Compreender a problemática ambiental, Conhecer as propostas de novos cenários sustentáveis e Compreender a complexidade ambiental e a importância da interdisciplinaridade.

O tema da sustentabilidade precisa ser discutido pelos futuros designers, apenas por meio de aulas expositivas dialogadas não é possível que os alunos compartilhem ideias e percebam o pensamento e contribuições dos colegas.

Os comentários dos alunos na sua maioria se apoiam no senso comum, isso pode ir mudando ao longo dos semestres se mais professores aplicassem estratégias para formar alunos com pensamentos mais sólidos. Isto se pode perceber nos alunos que no semestre passado já tiveram esta atividade. E nos alunos da turma mais avançada que tiveram maior compromisso e respeito pelos colegas.

O texto deve ser lido e comentado pelos alunos, capítulo a capítulo, facilitando assim a construção do conhecimento. As estratégias aplicadas visam à aprendizagem significativa dos alunos e possibilitar a apropriação do conhecimento. Percebe-se a necessidade de mudar o habitus de trabalho que existe entre o docente e discente universitário com predominância na exposição do conteúdo, em aulas expositivas.

\section{REFERÊNCIAS}

ANASTASIOU, Léa das Graças Camargos. Ensinar, aprender, apreender e processos de ensinagem. In. Processos de ensinagem na universidade: pressupostos para as estratégias de trabalho em aula. / organizado por ANASTASIOU e ALVES. 6. ed.- Joinville: UNIVILLE, 2006.

AUSUBEL, David P. Aquisição e Retenção de Conhecimentos: Uma Perspectiva Cognitiva. Portugal: Paralelo Editora, 2003.

BENEDITO, Antolí Vicente et al. La Formación universitária a debate. Barcelona: Universidad de Barcelona, 1995.

FREIRE, Paulo. Pedagogia da autonomia. Saberes necessários à prática educativa. São Paul: Ed. Paz e Terra, 1996.

GIL, Antonio Carlos. Metodologia do ensino superior. São Paulo: Atlas, 2008. 
MASETTO, Marcos T. Atividades pedagógicas no cotidiano da sala de aula universitária: reflexões e sugestões práticas. In Temas e textos em metodologia do ensino superior. Organizado por CASTANHO, Sergio e CASTANHO, Maria Eugenia. Papirus Editora, 83-102 pp. 2001

MOREIRA, Marco Antonio. Teorias de Aprendizagem. São Paulo: EPU, 1999.

PAZMINO, Ana Veronica. Modelo de ensino de métodos de design de produtos. Tese (doutorado) Pontifícia Universidade Católica do Rio de Janeiro, Departamento de Artes e Design, 2010.

PIMENTA, Selma Garrido; ANASTASIOU, Léa das Graças Camargos. Docência no Ensino Superior. São Paulo: Cortez, 2008.

TEIXEIRA, Gilberto. Elaboração de objetivos educacionais no ensino superior. In: Ser professor universitário, 2006. (http://www.serprofessoruniversitario.pro.br) 